Patients underwent DXA and REMS scans at the lumbar spine, according to the procedures described in Di Paola et al. [1], including an a-posteriori quality check of the examinations in order to guarantee the maximum reliability of the diagnostic outputs.

Three groups of patients were considered according to $\mathrm{BMI}:$ : underweight $\left(B M l<18.5 \mathrm{~kg} / \mathrm{m}^{2}\right)$, normal weight $\left(\mathrm{BMl} \geq 18.5 \mathrm{~kg} / \mathrm{m}^{2}\right.$ and $\left.<25 \mathrm{~kg} / \mathrm{m}^{2}\right)$, and overweight/obese $\left(B M I \geq 25 \mathrm{~kg} / \mathrm{m}^{2}\right)$. DXA and REMS BMD values were also stratified in 3 diagnostic categories: osteoporotic, osteopenic, or healthy.

The degree of correlation between DXA and REMS BMD values was quantified by calculating Pearson's correlation coefficient $(r)$. The diagnostic concordance between REMS and DXA was assessed by Cohen's $K$ considering the 3 diagnostic categories. REMS's sensitivity, specificity, positive predictive value (PPV) and negative predictive value (NPV) for discriminating patients with and without osteoporosis were also calculated using DXA outcomes as reference. The same statistics were calculated accepting a $0.3 \mathrm{~T}$-score tolerance on T-score values of borderline cases [1]

Results: Overall, 4282 patients were enrolled and, after the quality check, 3501 couples of scans were included in the analyses. Of these patients, $122(3.5 \%)$ were underweight, 1964 (56.1\%) were normal weight, and 1415 (40.4\%) were overweight. The results of the diagnostic performance in patients after BMI stratification are reported in Table 1.

Conclusion: We observed an excellent correlation between REMS-based diagnosis with respect to the osteoporosis diagnosis performed by DXA in patients from each BMI category. These results indicate that lumbar spine REMS analysis is a suitable and accurate diagnostic tool for patients with different BMI. REFERENCES:

[1] Di Paola M et al. Osteoporos Int. 2019 Feb;30(2):391-402.

Table 1. Diagnostic performance of REMS with respect to DXA considered as reference for patients of different body size.

\begin{tabular}{lccccccccccc}
\hline $\begin{array}{l}\text { BMI } \\
\text { categories }\end{array}$ & $r$ & \multicolumn{4}{c}{ No tolerance } & \multicolumn{4}{c}{ 0.3 T-score tolerance } \\
\cline { 2 - 10 } & & Sens. & Spec. & PPV & NPV & $K$ & Sens. Spec. PPV & NPV & $K$ \\
\hline Underweight & 0.946 & 97.5 & 91.5 & 86.8 & 98.4 & 0.89 & 98.2 & 93.2 & 89.2 & 99.3 & 0.91 \\
Normal weight & 0.946 & 92.6 & 94.4 & 87.0 & 96.9 & 0.85 & 97.5 & 96.7 & 92.3 & 99.0 & 0.93 \\
Overweight & 0.930 & 86.7 & 95.8 & 84.8 & 96.4 & 0.82 & 96.3 & 97.8 & 92.1 & 99.0 & 0.93
\end{tabular}

Abbreviations: $\mathbf{B M I}=$ body mass index; $\boldsymbol{r}=$ Pearson correlation coefficient; Sens. $=$ sensitivity Spec. = specificity; $\mathbf{P P V}=$ positive predictive value; $\mathbf{N P V}=$ negative predictive value; $\boldsymbol{K}$ Cohen's K.The authors BC, ED, ADP, ML, MM, XN, DOC are equal contributors listed in alphabetical order.

Disclosure of Interests: None declared

DOI: 10.1136/annrheumdis-2021-eular.2337

\section{POS1112 COMPARISON OF TWO APPROACHES IN FRACTURES RISK ASSESSMENT IN WOMEN WITH RHEUMATOID ARTHRITIS AND GLUCOCORTICOID USE}

N. Grygorieva ${ }^{1}$, V. Povoroznyuk ${ }^{1}{ }^{1}$ State Institution "D. F. Chebotarev Institute of Gerontology NAMS of Ukraine", Department of Clinical Physiology and Pathology of Locomotor Apparatus, Kyiv, Ukraine

Background: Nowadays, FRAX is the most useful tool for osteoporotic fracture risk assessment that is included in many guidelines. Rheumatoid arthritis (RA) and glucocorticoid (CG) use are two crucial factors for osteoporotic fractures included in FRAX algorithm. According to the last ACR guidelines for the treatment of GC-induced osteoporosis [1], it was recommended to divide the patients into three groups of fracture risk (high, medium and low) that have a great impact on treatment decision. Recently, we received own Ukrainian thresholds [2] for the national version of FRAX that are age-dependent and now widely used in clinical practice.

Objectives: Our study was aimed to compare two approaches (ACR-2017 and Ukrainian (2019) recommendations) in fracture risk assessment in women with RA and GC use.

Methods: We examined 195 females with RA aged 40-89 years old who took GC (at dose $\geq 5 \mathrm{mg} / \mathrm{d}$ for $\geq 3$ months) due to RA. The 10 -year probabilities of major osteoporotic (MOFs) and hip fractures (HFs) were calculated with and without bone mineral density (BMD) using the Ukrainian FRAX model [3]. The DXA was used to measure the lumbar spine, femoral neck and total body BMDs; $T$ and $Z$ scores were calculated (DISCOVERY Wi, Hologic, Inc., USA).

Results: FRAX indexes for MOFs and HFs without BMD in patients with RA and GC were (Me [25-75Q]) 12.0 [8.1-18.0] and 4.2 [1.7-7.2] \%. The correspondent FRAX indexes with BMD were 13.5 [8.5-20.0] and $5.1[1.8-8.7] \%$.

$50 \%$ of examined women had previous fractures and $20 \%$ had previous vertebral fractures. BMD of the femoral neck consisted of $0.62 \pm 0.13$ and L1-L4 BMD was $0.85 \pm 0.15 \mathrm{~g} / \mathrm{cm}^{2} .89 \%$ of females had low BMD at the lumbar spine and / or femoral neck ( $49 \%$ osteoporosis and $40 \%$ osteopenia).
$61 \%$ of women required antiosteoporotic treatment according to ACR-2017 guideline (17.4\% of them a had high risk of MOF and $43.1 \%$ moderate one) without BMD measurement and $64 \%$ of subjects after DXA scan.

According to Ukrainian national guideline, $57 \%$ of patients required antiosteoporotic treatment without BMD measurement and $42 \%$ - after additional DXA examination. After BMD measurement in subjects who required the DXA scan, $78.2 \%$ of females with RA and GC use required antiosteoporotic treatment (additionally to calcium and vitamin D, lifestyle modifications).

Conclusion: Approximately $60 \%$ of subjects with RA and GC use required antiosteoporotic treatment without additional DXA measurement according to correspondent FRAX indexes from both guidelines. The proportion of women requiring treatment after DXA scan is slightly higher according to Ukrainian recommendations. It proves that both of them can be used effectively in daily clinical practice for fracture risk assessment in females with RA.

\section{REFERENCES:}

[1] Buckley L, Guyatt G, Fink HA, Cannon M et al. 2017 American College of Rheumatology Guideline for the prevention and treatment of glucocorticoid-induced osteoporosis. Arthritis \& Rheumatology, 2017;69(8), 15211537. DOI:10.1002/art.40137

[2] Povoroznyuk V, Grygorieva N, Kanis JA et al. Ukrainian FRAX: criteria for diagnostics and treatment of osteoporosis. Pain. Joint. Spine. 2019;9(4):7-16 DOI: 10.22141/2224-1507.9.4.2019.191921

[3] Povoroznyuk VV, Grygorieva NV, Kanis JA et al. Epidemiology of hip fracture and the development of FRAX in Ukraine. Arch Osteoporos. 2017;12(1):53. DOI: 10.1007/s11657-017-0343-2.

Disclosure of Interests: Nataliia Grygorieva Consultant of: Servier, Redis, Vladyslav Povoroznyuk: None declared.

DOI: 10.1136/annrheumdis-2021-eular.2448

\section{POS1113}

ANTIRESORPTIVE THERAPY AFTER TERIPARATIDE DISCONTINUATION - WHEN IS THE BEST TIME TO STARTING IT?

M. Rato $^{1}$, F. Oliveira Pinheiro ${ }^{1}$, S. Garcia ${ }^{1}$, B. M. Fernandes ${ }^{1}$, D. Fonseca ${ }^{2}$, D. Santos Oliveira ${ }^{1,3}$, A. Martins ${ }^{1}$, F. R. Martins ${ }^{4}$, A. Bernardo ${ }^{1}$, R. Ferreira ${ }^{1}$, M. Bernardes ${ }^{1,5}$, L. Costa ${ }^{1} .{ }^{1}$ Centro Hospitalar Universitário de São João, Rheumatology, Porto, Portugal; ${ }^{2}$ Centro Hospitalar Vila Nova de Gaia/Espinho, Rheumatology, Vila Nova de Gaia, Portugal; ${ }^{3}$ Faculdade de Medicina da Universidade do Porto - FMUP, Center for Health Technology and Services Research (CINTESIS), Porto, Portugal; ${ }^{4}$ Centro Hospitalar Universitário do Algarve - Faro, Rheumatology, Faro, Portugal; ${ }^{5}$ Faculdade de Medicina da Universidade do Porto - FMUP, Rheumatology, Porto, Portugal

Background: Treatment with teriparatide (TPTD) is associated with reduction of fracture risk in patients with severe osteoporosis. This drug can only be used for up to 2 years. After that a treatment course with antiresorptives should be considered, in order to prevent the rebound of bone turnover observed after TPTD discontinuation. In this regard, interest in sequential osteoporosis therapy has grown in recent years but the ideal timing for starting another treatment after TPTD is not well established.

Objectives: The aim of this study is to assess if the timing of onset of antiresorptive therapy after TPTD discontinuation has implications in total hip bone mineral density (BMD) and in fracture risk.

Methods: We performed a retrospective cohort study that included patients with severe osteoporosis treated with TPTD $20 \mathrm{mcg} / \mathrm{day}$ for 24 months and followed for at least 2 more years in the rheumatology department of a tertiary university hospital. For analysis, demographic and clinical data and results of dual-energy X-ray absorptiometry (DXA) after cessation of teriparatide were used. For comparison between groups Mann-Whitney $U$ test was used.

Results: Fifty-five patients with osteoporosis, with a median age of 68 (32-85) years, were included. Forty-nine patients were female (89.1\%). Nineteen patients $(34.5 \%)$ had primary osteoporosis and 36 (65.5\%) glucocorticoid-induced osteoporosis. The median time for initiating antiresorptive treatment was $7(0-35)$ months after cessation of TPTD. Forty-three patients $(78.2 \%)$ started a bis phosphonate, 6 denosumab $(10.9 \%)$ and 6 patients did not receive any other treatment. The most prescribed bisphosphonate was zoledronate (69.8\%). All patients received calcium and vitamin D supplementation. After completion of TPTD regimen 8 patients experienced at least one fragility fracture (14.5\%). At follow-up, $37(67.3 \%)$ of patients underwent DXA on average $30.0 \pm 15.4$ months after starting antiresorptive agents. The median total hip BMD in patients who started antiresorptive therapy in the first 12 months (inclusive) after cessation of TPTD regime was $0,738(0.587-0.993) \mathrm{g} / \mathrm{cm}^{2}$ and the median total hip BMD of patients who started therapy after one year of discontinuation of TPTD was $0.683(0.390-0.813) \mathrm{g} / \mathrm{cm}^{2}$. This difference is marginally significant $(\mathrm{p}=0.067)$ The median time in starting antiresorptive treatment is higher in patients with new fragility fractures after TPTD than in patients without new fractures however this difference was not statistically significant (10.0 [2-35] vs $6.0[0-35]$ months; $p=0.393$, respectively). 